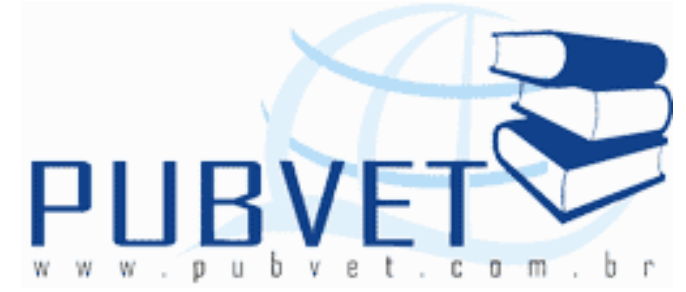

PUBVET, Publicações em Medicina Veterinária e Zootecnia.

\title{
Controle de infecção cirúrgica: contaminação em centro cirúrgico de pequenos animais
}

\author{
Maria Eugenia Moraes ${ }^{1}$, Angélica do Rocio Carvalho Silva ${ }^{2}$, Maria Raquel de \\ Godoy Oriani ${ }^{2}$, Priscila Carvalho de Oliveira ${ }^{3}$
}

1 Mestranda do Departamento de Patologia Experimental e Comparada, Faculdade de Medicina Veterinária e Zootecnia (FMVZ), Universidade de São Paulo (USP), Av. Prof. Dr. Orlando Marques de Paiva 87, Cidade Universitária, São Paulo, SP, CEP 05508-000 - eugeniavet@gmail.com

${ }^{2}$ Doutora - Docente de Ensino Superior - UNIFEOB (São João Da Boa Vista) e FESB (Bragança Paulista)

${ }^{3}$ Doutora - Docente de Ensino Superior - UNIFEOB (São João Da Boa Vista)

\section{Resumo}

A hospitalização de animais doentes aumenta muito o risco de ocorrência de infecções. O médico veterinário tem a obrigação de minimizar o risco de danos adicionais que podem ser subseqüentes às suas intervenções e isso inclui minimizar a exposição dos pacientes a agentes infecciosos que podem levar à infecção nosocomial, considerando que, em alguns casos, o agente infeccioso pode ser zoonótico. O objetivo deste trabalho foi avaliar os níveis de contaminação no centro cirúrgico de Pequenos Animais do Hospital Veterinário do Centro Universitário da Fundação de Ensino Octávio Bastos (Unifeob), em São João da Boa Vista, SP, e desenvolver um projeto educacional, focando os 
pontos críticos que surgiram a fim de que se mantenha o controle de infeç̧ão cirúrgica em Pequenos Animais. Nos resultados obtidos pode-se observar que nas coletas feitas no ambiente cirúrgico durante a noite há um grande crescimento de fungos. Nas amostras colhidas da mesa e do chão, na maioria das vezes houve crescimento de fungos e bactérias, com exceção das amostras colhidas após a cirurgia, na qual se pode dizer que houve predomínio no crescimento de bactérias. Observou-se também que o maior número de colônias foi encontrado na placa que ficava próxima à porta do centro cirúrgico, em relação às outras distribuídas pela sala, devido ao maior trânsito de pessoas. Também se obteve um resultado positivo modificando-se a rotina de calçamento de luvas, que foi sugerida como medida para diminuir a contaminação que era encontrada nas luvas do cirurgião imediatamente antes da cirurgia.

Palavras-chave: infecção hospitalar, prevenção, controle, veterinária, cirurgia.

\title{
Surgical infection control: contamination in the operation room of small animals
}

\begin{abstract}
The hospitalization of ill animals increases the risk of infections. The veterinarian has the obligation to minimize the risk of additional damage that could be subsequent to their interventions and that includes minimizing patient exposure to infections that could lead to a nosocomial infection, considering that, in some cases, the infection can be zoonotic. The main goal of this work was to evaluate the contamination levels in the operation room of small animals of the Veterinary Hospital of the University Center of the Octavio Bastos Educational Foundation (Unifeob), in São João da Boa Vista, SP, and to develop an educational project that focus the critical points that arose in order to maintain surgical infection control in Small Animals. Results show that in the samples took in the surgical environment during the night there is a great risk
\end{abstract}


of fungus growth. In the samples that were taken from the table and floor, the majority of the time, there was fungus and bacteria growth, with the exception of the samples took after surgery, in which case you can say that there was predominant growth of bacteria. It was also observed that the largest number of colonies were found in the plaque next to the operation room door, in comparison to the other doors around the room due to greater transit of people. A positive result was obtained by changing the pavement gloves routine that suggested as a way to decrease the contamination that was found in the gloves immediately before the surgery.

Keywords: hospital infection, prevention, control, veterinary, surgical.

\section{INTRODUÇÂO}

A hospitalização de animais doentes aumenta muito o risco de ocorrência de infecções. O médico veterinário tem a obrigação de minimizar o risco de danos adicionais que podem ser subseqüentes às suas intervenções e isso inclui minimizar a exposição dos pacientes a agentes infecciosos que podem levar à infecção nosocomial. As infecções nosocomiais em hospitais veterinários não causam problemas unicamente ao paciente afetado, pois a propagação dos agentes infecciosos pode também prejudicar as operações normais do hospital, a confiança do cliente, a imagem pública da Instituição, além de que, em alguns casos, o agente infeccioso pode ser zoonótico (MORLEY, 2002)

A maioria dos profissionais da área de saúde não busca informações, nem orientações sobre prevenção e controle de infecção, nem sobre seguridade ocupacional e muito menos ainda, adota postura adequada nesse sentido. Visando suprir essa lacuna, o ensino destes tópicos é discutido por vários autores.

Para definir a melhor maneira de se ensinar o controle de infecção no ambiente hospitalar, alguns defendem a idéia de que uma disciplina específica seja ministrada, enquanto outros acreditam que esse conteúdo deve 
MORAES, M.E. et al. Controle de infecção cirúrgica: contaminação em centro cirúrgico de pequenos animais. PUBVET, Londrina, V. 6, N. 25, Ed. 212, Art. 1415, 2012.

ser abordado durante todo o curso, permeando cada disciplina ou especialidade. Há ainda quem defenda que devido à complexidade do conteúdo, este deve fazer parte de uma especialização (TIPPLE, 2003).

Entretanto, independentemente da estrutura e forma curricular adotada, Tiplle (2003) aponta que o controle e a prevenção de infecção devem fazer parte da filosofia da formação dos profissionais da área da saúde. Além disso, - autor complementa que, para que os profissionais estejam permanentemente atualizados, estes conteúdos devem fazer parte do processo de educação continuada durante o exercício profissional.

Em 1847, foi estabelecida por Semmelweis, o que talvez tenha sido a primeira medida profilática em forma de rotina escrita em uma instituição de ensino da área de saúde: esta determinava que todo estudante ou médico proveniente da sala de Anatomia seria obrigado a lavar as mãos com solução de ácido clorídrico, em bacia colocada na entrada das salas de clinica obstétrica (TIPPLE, 2003).

Segundo Macedo et al. (2003), apesar da sua relativa simplicidade a higiene manual é o procedimento mais importante para o controle da infecção hospitalar.

Atualmente, inúmeras descobertas possibilitaram o conhecimento da causa, epidemiologia e profilaxia de infecções, contudo todos esses avanços não colocam os profissionais da área em situação muito diferente da época de Ignaz Semmelweis, no que se refere à adesão a medidas simples de controle de infecção, como a lavagem das mãos proposta por ele, além de que existem novos desafios relacionados à infecção, como os agentes infecciosos emergentes, a resistência microbiana e as conseqüências das transições demográficas e epidemiológica (TIPPLE, 2003).

Segundo Pereira et al. (1996), em hospitais humanos, as taxas de infecção hospitalar (IH) variam com o tipo de vigilância empregado e também com o porte e categoria do hospital, sendo geralmente mais altas em hospitais de grande porte e nos de ensino. De acordo com os autores, o fato de os hospitais de ensino serem mais vulneráveis à IH pode se explicar pelo tipo de 
MORAES, M.E. et al. Controle de infecção cirúrgica: contaminação em centro cirúrgico de pequenos animais. PUBVET, Londrina, V. 6, N. 25, Ed. 212, Art. 1415, 2012.

clientela, a pluralidade de doentes com diferentes diagnósticos, a permanência prolongada dos pacientes na instituição para atender objetivos didáticos e também ao número elevado de pessoas exercendo diversas atividades (desde funcionários da instituição, até estudantes de diferentes níveis e cursos), o que gera aumento do fluxo de entrada e permanência de pessoas no hospital. Para o controle da IH a atenção dos profissionais deve estar direcionada as medidas profiláticas e de controle. Através de um estudo analítico de dados coletado por questionários enviados para 110 Hospitais de Ensino e ou Centro de Treinamento para o controle da IH, de 21 estados do Brasil, Pereira et al. (1996) concluíram que existe certo descomprometimento, por parte de vários profissionais e dirigentes de hospitais em relação a estas questões, sendo portanto necessária, a elaboração de programas educativos.

O meio ambiente hospitalar, incluindo a água, o ar e as superfícies inanimadas que cercam o paciente, está intimamente relacionado com as infecções hospitalares, podendo proporcionar focos de contato e de transmissão. Uma das atividades executadas nos hospitais para manter o ambiente biologicamente seguro é a limpeza de unidade, ou seja, limpeza do conjunto de espaços e de móveis destinados a cada paciente variando seus componentes de hospital a hospital (ANDRADE et al., 2000). A literatura tradicional de enfermagem distingue dois tipos de limpeza de unidade, sendo essas a concorrente, que é feita diariamente em algumas partes da unidade e em objetos pessoais após o seu uso, e a terminal, que é realizada em todos os componentes da unidade e tem sido indicada quando o paciente desocupa o leito por motivo de alta, óbito, transferência, período de hospitalização prolongada e nos casos de término de isolamento

Na limpeza de unidade tem sido recomendado o uso de produtos químicos com ação germicida, eficazes para remoção e destruição de microorganismos existentes. No Brasil, pela orientação legal, os produtos indicados devem possuir princípios ativos fenólicos, ou compostos orgânicos e inorgânicos liberadores de cloro ativo, ou princípios quaternários de amônia ou de álcoois, ou outros que atendam a legislação específica (ANDRADE et al., 2000). 
Andrade et al. (2000) avaliaram as condições microbiológicas dos colchões de um hospital geral, público e voltado ao ensino e pesquisa, localizado em uma cidade no interior do estado de São Paulo, antes e depois da limpeza de unidade terminal de pacientes. As amostras foram colhidas de $20 \%$ dos leitos ativos, sendo que para ser selecionado o colchão tinha que estar vago por óbito, alta ou transferência e não ter sido limpo. Utilizaram-se para a colheita placas de contato - Rodac-plate - com meio de cultura ágar sangue. A limpeza, após a primeira coleta, foi realizada pelos integrantes da equipe de enfermagem pela fricção manual associada ao uso de solução detergentedesinfetante de fenol sintético. Foram analisados 52 colchões, totalizando 520 placas, sendo que $514(98,8 \%)$ apresentaram culturas positivas, das quais 259 eram do período anterior a limpeza e 255 ao período posterior à mesma. Os pesquisadores constataram que houve redução de apenas quatro placas positivas, o que sugere que a limpeza como foi feita, deslocou a carga microbiana para outros pontos do colchão em vez de diminuí-la.

De acordo com Andrade et al. (1992), consideram-se como principais causas de infecção hospitalar o mau uso da antibiótico terapia, uso de técnicas diagnosticas e terapêuticas violentas, diversidade de pessoas lidando com o mesmo paciente, além de fatores agravantes como a contratação de pessoas destreinadas para prevenção de infecções. Contudo esses conceitos sobre causas de infecção são baseados em estudos feitos em hospitais humanos. Esses autores portanto, realizaram um estudo para isolar e identificar bactérias a partir do ambiente de um hospital veterinário, das pessoas envolvidas no trabalho hospitalar e das feridas cirúrgicas de cães e puderam concluir que o ambiente hospitalar incluindo a sala e mesa cirúrgica e as mãos dos médicos veterinários podem desempenhar um papel importante nas infecções hospitalares.

Em relação ao centro cirúrgico o controle da contaminação ambiental não se limita à limpeza de pisos, paredes e equipamentos, abrangendo também o controle do acesso de pessoas à sala e seu trânsito dentro da mesma durante a cirurgia, o sistema de ventilação, a movimentação das portas e a 
paramentação adequada da equipe cirúrgica. A infeç̧ão do sítio cirúrgico é multifatorial, sendo a equipe cirúrgica uma importante fonte de patógenos, assim o uso da paramentação é uma forma de prevenção de contaminação e infecção, tanto para o paciente quanto para o profissional (CATANEO, 2004).

Tanaka et al. (2007) incluem um outro agente à lista de fatores envolvidos no processo de infecção hospitalar. Eles verificaram que as formigas podem ter papel importante na veiculação de bactérias no ambiente hospitalar. Estes autores coletaram formigas assepticamente, em vários setores do Hospital das Clínicas e do Hemocentro da Faculdade de Marília (SP) e através de cultura bacteriana, isolaram em todas as amostras, bacilos gram positivos, em 62,5\% das amostras isolaram Klebsiella pneumoniae, Klebisiella azaenae e Escherichia Coli.

As infecções fúngicas de origem hospitalar passaram a ser de grande importância nos últimos anos, devido ao aumento progressivo em sua ocorrência e pelas altas taxas de morbidade e mortalidade causadas por estes microorgansmos. Estas infecções podem ter origem endógena ou exógena, como pelas mãos dos profissionais ou ainda a partir de fontes ambientais. Deste modo, o monitoramento de fontes ambientais deve ser realizado, especialmente em salas especiais com pacientes imunocomprometidos (MARTINS- DINIZ et. al., 2005).

A infecção hospitalar é um problema grave e que vem crescendo em complexidade e em incidência. Foi realizado um trabalho com o intuito de identificar a incidência de infecção do sitio cirúrgico e os fatores de risco de pacientes submetidos a cirurgias eletivas na especialidade de gastroenterologia realizadas em um hospital humano público do interior paulista. A taxa de incidência de infecção do sitio cirúrgico encontrada foi de $13,4 \%$, sendo esta faixa considerada próxima a aceitável para cirurgias potencialmente contaminadas. Além disso, alguns fatores de risco estavam presentes em 50\% dos casos de infecção de sitio cirúrgico detectados, são eles: idade acima de 50 anos, presença de neoplasias, duração da cirurgia maior que duas horas e tricotomia inadequada. Assim esse trabalho confirma a importância de medidas 
para a prevenção e controle de infecção de sitio cirúrgico (POVEDA et al.,2003).

Segundo Medeiros et al. (2003) apesar dos grandes avanços em todas as áreas da cirurgia o controle da infecção ainda é um grande desafio, sendo que a profilaxia pode ser considerada o maior aliado do cirurgião para manter a infecção sob controle. Estes autores afirmam também que a infecção cirúrgica é uma entidade clínica em que se têm vários fatores envolvidos e que para reduzir e controlar sua incidência é necessário aplicar medidas preventivas, educacionais e de controle epidemiológico.

O objetivo deste trabalho foi, portanto, avaliar os níveis de contaminação no centro cirúrgico de Pequenos Animais do Hospital Veterinário do Centro Universitário da Fundação de Ensino Octávio Bastos (Unifeob), em São João da Boa Vista, SP, focando os pontos críticos que surgiram a fim de que se mantenha o controle de infecção cirúrgica em Pequenos Animais.

\section{MATERIAIS E MÉTODOS}

A pesquisa foi desenvolvida no Hospital Veterinário da Faculdade de Medicina Veterinária do Centro Universitário da Fundação de Ensino Octávio Bastos (Unifeob), em São João da Boa Vista, SP.

Foram coletadas em 12 cirurgias, por meio de swabs, amostras da mesa e do chão após a limpeza do centro cirúrgico (no dia anterior à cirurgia), na manhã da cirurgia, antes da cirurgia e após a cirurgia. Foram coletadas amostras das luvas do cirurgião antes da cirurgia. Além disso, a partir da terceira cirurgia acompanhada foram coletadas amostras do material cirúrgico que seria usado, essa coleta era feita logo após a caixa de material cirúrgico ser aberta. As amostras foram inoculadas no meio Thioglycollate broth e incubadas a $25^{\circ} \mathrm{C}$ durante sete dias.

Após a limpeza do centro cirúrgico (no dia anterior a cirurgia) era colocada uma placa de Petri com o meio de cultura Brain heart ágar (BHI) que permanecia no centro cirúrgico durante toda a noite. No período de duração da 
cirurgia eram colocadas mais três placas de Petri com este mesmo meio em diferentes paredes do centro cirúrgico para que fosse avaliada a contaminação do ambiente. As três placas que eram colocadas na parede do centro cirúrgico eram dispostas da seguinte forma: a primeira placa era colocada próxima a porta do centro cirúrgico, a segunda na parede logo abaixo do ar condicionado e a terceira na parede em frente à porta do centro cirúrgico. Essas amostras também eram incubadas a $25^{\circ} \mathrm{C}$ durante sete dias.

As duas primeiras coletas foram feitas em dezembro de 2007 e após serem avaliados os resultados obtidos durante essas duas cirurgias, foram propostas medidas em conjunto com a equipe hospitalar, nos pontos em que se observaram contaminações, com o intuito de minimizar a contaminação e educar os alunos, funcionários e equipes cirúrgicas.

Assim foram feitas coletas de acompanhamento de uma cirurgia por mês até dezembro de 2008.

Para a escolha deste protocolo de pesquisa, um piloto foi realizado no período de outubro a novembro de 2006 , fazendo coletas de quatro cirurgias.

\section{RESULTADOS}

Nas placas que permaneceram à noite no centro cirúrgico observou-se um grande crescimento de fungo. Nas placas colocadas durante a cirurgia houve predominância do crescimento de fungos em relação a bactérias, no entanto o número de colônias fúngicas presentes era menor quando comparados às placas que permaneceram à noite. Nos swabs coletados do chão e da mesa cirúrgica não foi observada muita diferença já que na maioria das coletas houve presença de fungos e bactérias, contudo pode-se perceber que nas amostras colhidas após a cirurgia houve predomínio de bactérias, já que se observaram bactérias nas 12 coletas feitas do chão e em 10 coletas da mesa, enquanto que a presença de fungo ocorreu em apenas duas amostras da mesa e sete amostras do chão. 
Em uma das coletas feitas foi observada na placa de BHI que permanecia a noite no centro cirúrgico grande número de formigas, isso foi informado à direção de hospital para que pudesse ser feita a dedetização do ambiente.

Na placa que ficava próxima a porta do centro cirúrgico foi observado um maior número de colônias em comparação com as outras placas.

Antes da escolha do protocolo de pesquisa, durante o estudo piloto, foi detectada, na primeira coleta a presença de bactérias na luva do cirurgião, imediatamente antes do início da cirurgia. As luvas eram calçadas na sala de paramentação e vinham expostas ao ar ambiente desde a mesma, até a sala cirúrgica. Nas demais coletas a luva passou a ser calçada dentro do centro cirúrgico e não foi mais detectada contaminação.

A figura 1 ilustra a porcentagem de coletas positivas para bactérias e fungos encontradas durante o estudo, sendo Ambiente 1 a placa de BHI que permanecia durante a noite no centro cirúrgico; Ambiente 2 a placa de BHI que ficava próxima a porta durante a cirurgia; Ambiente 3 a placa de BHI que ficava logo abaixo do ar condicionado durante a cirurgia; Ambiente 4 a placa de BHI que ficava na parede em frente a porta do centro cirúrgico. Chão $1 \mathrm{e}$ Mesa 1 correspondem aos swabs colhidos na tarde anterior a cirurgia;Chão 2 e Mesa 2 as coletas feitas na manhã da cirurgia; Chão 3 e Mesa 3 as coletas feitas antes do inicio da cirurgia e Chão 4 e Mesa 4 as feitas após a cirurgia. A Luva corresponde a coleta realizada na luva do cirurgião antes do inicio da cirurgia e o Material corresponde a coleta feita do material cirúrgico antes da cirurgia. 


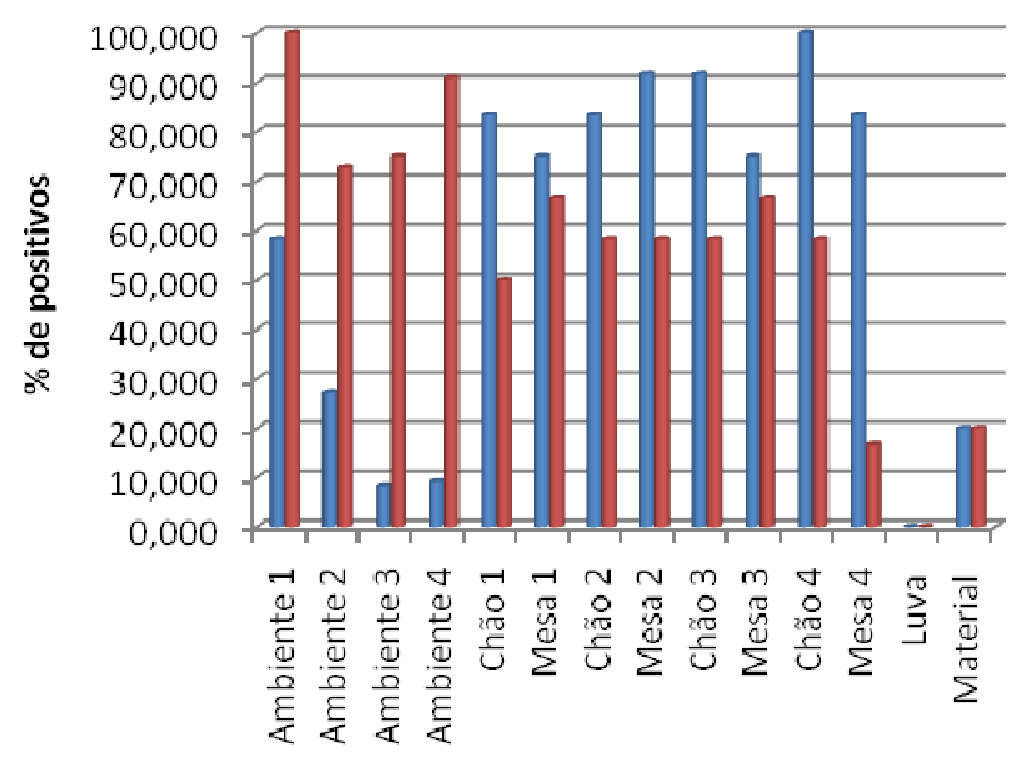

- $\%$ de coletas positivas para bactérias

q $\%$ de coletas positivas para fungos

Figura 1: Porcentagem de coletas positivas para Bactérias e Fungos das cirurgias acompanhadas $(n=12)$

\section{DISCUSSÃO}

Em relação às placas de BHI que ficavam nas paredes do centro cirúrgico, foi observado um maior crescimento de microrganismos na placa próxima a porta do centro cirúrgico e isso pode ser explicado pelo grande fluxo de pessoas no centro cirúrgico, já que se trata de um hospital de ensino. Além disso, o fato do hospital ser de ensino faz com que muitas vezes o tempo de duração da cirurgia seja prolongado para fins didáticos, como por exemplo explicar e mostrar aos estudantes os procedimentos que estão sendo realizados, sendo que quanto mais longa uma cirurgia maiores as chances de que o animal venha a ter uma infecção. Segundo Pereira et al. (1996), em hospitais humanos, as taxas de infecção hospitalar (IH) geralmente são mais altas em hospitais de grande porte e nos de ensino. De acordo com esses autores, o fato de os hospitais de ensino serem mais vulneráveis à IH pode se explicar pelo tipo de clientela, diagnósticos variados, permanência dos 
pacientes na instituição para atender objetivos didáticos e também ao número elevado de pessoas exercendo diversas atividades.

Insetos como formigas podem ter podem ter papel importante na veiculação de bactérias no ambiente hospitalar, conforme Tanaka et al. (2007), portanto, após terem sido encontradas formigas em uma das coletas na placa de $\mathrm{BHI}$ que permanecia a noite no centro cirúrgico a direção do hospital foi informada para que fosse realizada a dedetização. O problema não foi mais encontrado nas coletas posteriores.

$\mathrm{Na}$ placa de BHI que permanecia a noite no centro cirúrgico foi observado grande crescimento de fungos e nas placas que permaneciam durante a cirurgia também eram observados fungos. De acordo com Martiz-Dinis et. al. (2005) as infecções fúngicas de origem hospitalar são de grande importância por estarem aumentando muito em número de ocorrências, nos últimos anos pelas altas taxas de morbidade e mortalidade.

Cataneo (2004) afirma que em relação ao centro cirúrgico o controle da contaminação ambiental não se limita à limpeza mas inclui também o controle do acesso e do trânsito das pessoas nas áreas cirúrgicas, o sistema de ventilação, a movimentação das portas e a paramentação adequada da equipe cirúrgica. Isso condiz com o fato de no presente trabalho a placa perto da porta ter uma maior contaminação e nesse caso é um desafio diminuir está contaminação já que o acesso de pessoas não é restrito por se tratar de um hospital de ensino.

Quanto à contaminação detectada na luva do cirurgião durante o projeto piloto, foi sugerido como medida para diminuir a contaminação, que a luva não fosse mais colocada na sala de paramentação, mas no centro cirúrgico evitando que a luva fosse contaminada durante o trajeto entre as duas salas. O procedimento mostrou-se eficaz, pois após a adoção desta medida as amostras colhidas da luva foram todas negativas. 
MORAES, M.E. et al. Controle de infecção cirúrgica: contaminação em centro cirúrgico de pequenos animais. PUBVET, Londrina, V. 6, N. 25, Ed. 212, Art. 1415, 2012.

\section{CONCLUSÃO}

Com deste trabalho pode-se concluir que o controle de infecção hospitalar depende de vários fatores, especialmente ao se tratar de infecção cirúrgica. Dentre estes fatores podemos citar: limpeza adequada do ambiente, ventilação adequada, paramentação adequada da equipe e controle do fluxo de pessoas.

Como este trabalho foi realizado em um hospital de ensino o controle do fluxo de pessoas torna-se uma questão complexa. Contudo sugere-se que este fluxo seja evitado especialmente após a cirurgia já ter sido iniciada, uma vez que encontramos uma contaminação bem maior na placa de BHI que ficava próxima à porta comparada com as outras placas no ambiente.

Ressalta-se também que a medida tomada de calçar as luvas dentro do centro cirúrgico e não mais na sala de paramentação diminuiu as chances de contaminação da luva.

Vale ressaltar que a prevenção e o controle de infecção deve ser uma preocupação de todos os profissionais da área da saúde e que cabe a cada um se manter atualizado sobre o assunto, além disso a importância da prevenção e do controle de infecção deve ser deve ser passado aos estudantes da área e programas educativos devem ser realizados neste sentido.

Ao se realizar a revisão bibliográfica para esta pesquisa, percebeu-se que existem poucos estudos sobre prevenção e controle de infecção hospitalar na veterinária e por isso concluímos que é importante que mais pesquisas sejam realizadas.

\section{REFERÊNCIAS BIBLIOGRAFICAS}

ANDRADE, D.; ANGERAMI, E. L. S.; PADOVANI, C .R. Condição microbiológica dos leitos hospitalares antes e depois de sua limpeza. Revista de Saúde Pública, São Paulo, v. 34, n. 2, p.163-9, abr. 2000.

ANDRADE, M. A. et al., Freqüência de bactérias isoladas no ambiente, em feridas cirúrgicas, em médicos veterinários, enfermeiros e auxiliares de enfermagem. I - Infecção em hospital veterinário. Anais das Escolas de Agronomia e Veterinária - Universidade Federal de Goiás, v. 21/22, n.1, p. 101-111 jan/ dez. 1991/92. 
CATANEO, C. et al., O Preparo da Equipe Cirúrgica: Aspecto Relevante no Controle da Contaminação Ambiental. Revista Latino Americana Enfermagem, p.283. março/abril 2004.

MACEDO, J. et al.; RODRIGUES, M. T.; NASCIMENTO-CARVALHO, C. M. C. Perspectivas no Controle da Infecção Hospitalar. Jornal de Pediatria, Porto Alegre, v.79, n.3, p. 277-278, Maio/ Junho 2003.

MARTIZ-DINIZ, J. N. et. al. Monitoramento de fungos anemófilos e de levaduras em unidade hospitalar. Revista de Saúde Pública. V. 39, n.3, p. 398-405, 2005.

MEDEIROS, A. da C. et. al., Infeç̧ão hospitalar em pacientes cirúrgicos de hospital veterinário. Acta Cirúrgica Brasileira, São Paulo, v.18, 2003.

MORLEY, P. S. Bioswcury of Veterinary pratices, Veterinary Clinics of North America: Food Animal Practice, v.18, 2002.

PEREIRA, M. S; Moriya, T. M.; GIR, E. et. al., Infecção hospitalar nos hospitais escola: Uma análise sobre seu controle, Revista Latino-Americana de Enfermagem. Ribeirão Preto, $v$. 4, n. 1, p. 45-62, jan. 1996.

POVEDA, V. B.; GALVÃO, C. M.; HAYASHIDA, M. Análise dos fatores de risco relacionados a incidência de infecção do sítio cirúrgico em gastrocirurgias, Revista da Escola de Enfermagem da USP, São Paulo, v.37, 2003.

TANAKA, I. I.; VIGGIANI, A. M.F.S.; PERSON, O. C. Bactérias veiculadas por formigas em ambiente hospitalar. Arquivos Médicos do ABC. v. 32, n.2, p. 60- 63, 2007.

TIPPLE, A. F. V., O Ensino do Controle de Infecção: Um ensaio teórico-prático, Revista Latino-Americana de Enfermagem. v. 11, n.2, p. 245-250. março/ abril 2003. 